\title{
Study on non-buckling steel plate shear walls with corrugated core panel
}

\author{
H. J. Jin ${ }^{\mathrm{a} *}$, G.Q. Li ${ }^{\mathrm{b}}$ and F.F. Sun ${ }^{\mathrm{b}}$ \\ ${ }^{a}$ College of Civil Engineering, Tongji University, China \\ bState Key Laboratory of Disaster Reduction in Civil Engineering, Tongji University, China \\ *corresponding author, e-mail address: hj2in@tongji.edu.cn
}

\begin{abstract}
In this paper, a non-buckling steel plate shear wall with corrugated core panel was introduced, which keeps itself from premature buckling by fully taking advantage of extralarge flexural stiffness of corrugated core panel and enables to yield before buckling. Most importantly, the optimal corrugation configuration of corrugated core panel was obtained by parametric investigation into detailed dimensions of single wave such as thickness, depth of corrugation, angle of corrugation and so on, which was hereafter validated by numerical simulation. Non-dimensional parameters such as height-to-thickness ratio, width-to-thickness ratio and aspect ratio have also been taken into consideration, all of which turn out to be the most decisive factors of guaranteeing the "non-buckling". The parametric analysis proves that as long as the former two factors are below the critical values recommended in this paper, unexpected buckling is not going to happen. On the other hand, theoretical approaches to calculate the yielding strength and initial stiffness were derived, as well as a theoretical design method for boundary elements. Meanwhile, a simplified model was concluded. Formulas to determine the cross-section of cross braces and boundary elements were given based on the principle of equivalent yielding strength and initial stiffness. Finally, four specimens were resorted to testify above theory and parametric study. Two specimens with larger height-to-thickness ratio that exceeds the recommended limit exhibit inevitable buckling, while the others with smaller height-tothickness ratio show ideal energy-absorbing capability and no evident buckling is observed even under an inter-story drift of $2 \%$.
\end{abstract}

Keywords: Non-buckling; corrugated core panel; optimal corrugation configuration; theoretical approach; simplified model; experimental investigation.

\section{Introduction}

Corrugated steel plates have been widely used in the field of civil engineering, architecture, marine transportation, container body and web plates in bridge girders etc., because these are found to be more efficient in providing stiffness and strength within the same steel consumption compared to ordinary flat ones, such as higher stiffness-to-weight ratio and strength-to-weight ratio, due to the geometry configuration, which endows itself higher structural rigidity. Therefore, for a better structural performance, corrugated plates have been well recommended in many ways. A case in point is the application in steel plate shear walls.
As is well documented, traditional steel plate shear walls (denoted as SPWs) have been used so popularly as lateral resisting structural members in tall buildings during the past few decades. However, SPWs tend to buckle at a premature stage, resulting from the inadequate out-of-plane flexural stiffness. Once it buckles, the stiffness and strength deteriorate swiftly to a large extent, as well as its hysteretic performance [1]. Thus, buckling restrainers are innovatively introduced to SPWs. In most cases, buckling restrainers of buckling-restrained steel plate shear walls (denoted as BRWs) are at the two sides of core panel like a "sandwich", and designed by corresponding method $[2,3]$ which could offer extra large out-of-plane flexural stiffness to flat core panel and successfully fulfill 
buckling restraining. Inspired by inherently large out-of-plane flexural stiffness of corrugated steel panel, researchers from all over the world have paid more and more attention to the behavior of steel plate shear walls with corrugated core panel.

Early work on corrugated steel diaphragms was first carried out in 1960 [4], which was then improved and extended consequently in the following decades [5, 6]. Fazio et al [7] extended Easley's theory and developed simple formulas to predict shear capacity with any type of fasteners, whether weld, rivets, or screws. A general solution was presented for the flexibility of profiled metal sheeting of arbitrary cross section subjected to in-plane shear force [8]. Behavior of corrugated steel sheeting under inplane shear force was continuingly studied and its analytical models for shear strength and stiffness kept on developing and were validated [9]. A full-scale shear test on wall panels with corrugated steel plate was conducted, as well as a numerical equivalent model for hysteretic behavior was brought forward $[10,11]$. A total of 44 cyclic racking tests were carried out [12], based on which a thorough glimpse into behavior of corrugated steel shear walls was then provided. The tests, both were conducted monotonically and cyclically, on corrugated shear walls were also conducted [13]. The parameters taken into consideration included thickness of corrugated steel plate, the fastener size and spacing and the boundary stud member configuration. Similar research work also had been carried out by Emami [14] and Shimizu [15].

Although a huge amount of work, both theoretical and experimental, has been done so far, the attention is only focused on corrugated steel panel with ordinary corrugation configuration, which inevitably leads to elastic buckling and to a loss of energy absorption capacity. Thus, in order to improve its hysteretic performance, the corrugation configuration is parametrically studied, as well as its theoretical model, which aims to predict the yielding strength and initial stiffness precisely. For the first time, non-buckling steel plate shear wall with corrugated core panel (denoted as $\mathrm{NCW}$ ) is brought forward in this paper, which typically consists of two main parts, the corrugated core panel with optimal corrugation configuration and boundary elements, as shown in Fig. 1.

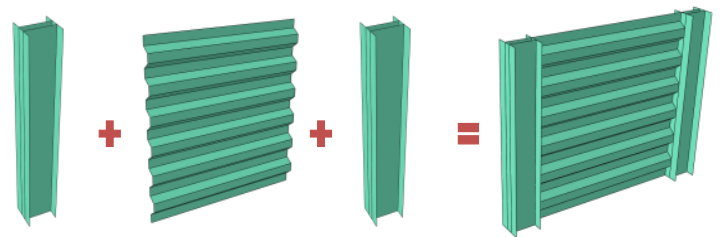

Fig. 1. Components of non-buckling steel plate shear wall with corrugated core panel (NCW)

\section{Optimal corrugation configuration}

\subsection{Finite element model of $\mathrm{NCWs}$}

Several parameters are considered in order to obtain the optimal corrugation configuration, such as wave length $a$, angle of corrugation $\theta$, depth of corrugation $d$ and so on. Detailed dimensions of single wave are depicted in Fig. 2. Ten typical configurations are selected to perform finite element analysis (denoted as FEA), as shown in Table 1.

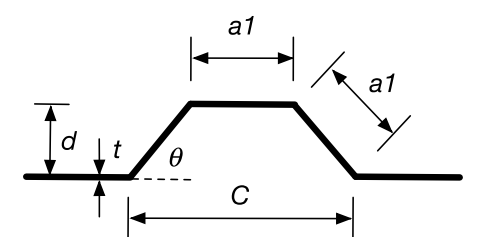

Fig. 2. Detailed dimensions of single wave

Table 1. Parameters of ten typical configurations

\begin{tabular}{cccc}
\hline Wave No. & $\boldsymbol{a 1}$-mm & $\boldsymbol{\theta}$-degree & $\boldsymbol{d}$-mm \\
\hline 1 & 60 & 30 & 30 \\
2 & 90 & 42 & 60 \\
3 & 120 & 30 & 60 \\
4 & 90 & 42 & 60 \\
5 & 120 & 49 & 90 \\
6 & 150 & 37 & 90 \\
7 & 150 & 53 & 120 \\
8 & 180 & 42 & 120 \\
9 & 210 & 35 & 120 \\
10 & 105 & 53 & 84 \\
\hline
\end{tabular}

Abaqus [16] is used to execute the parametric study, in which the thickness $(t)$ of corrugated core panel is $6 \mathrm{~mm}, 9 \mathrm{~mm}$ and $12 \mathrm{~mm}$, while its width $(B)$ and height $(H)$ are both $2000 \mathrm{~mm}$. The boundary element is H-section, $200 \mathrm{~mm}$ in height and $200 \mathrm{~mm}$ in width. Its web is as thick as the core panel and the flanges are $20 \mathrm{~mm}$. Each part was made from Q235, a commonly-used structural steel in China, and modelled by 8 -node linear solid elements (C3D8).

\subsection{FEA results}

FEA results show that the corrugation configurations with a big value of $\theta$ and small 
value of height-to-thickness ratio $(H / t)$ or widthto-thickness ratio $(B / t)$, such as Wave No.7 and No.10, exhibit excellent hysteretic performance even under a maximum drift ratio of $2 \%$, as shown in Fig. 3 and Fig. 4. The stress contours also indicate that no out-of-plane buckling have taken place, as shown in Fig. 5 and Fig. 6. For those imperfect corrugation configurations, no matter how small the $H / t$ and $B / t$ ratios are assigned, they are still apt to buckle at an early stage. Typical hysteretic curve and stress contour are presented in Fig. 7 and Fig. 8, respectively.

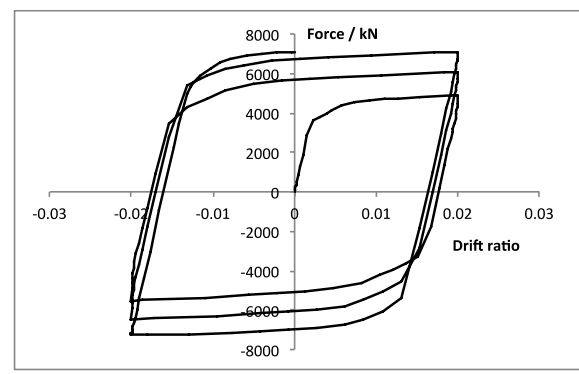

Fig. 3. Hysteretic performance of No.7 wave

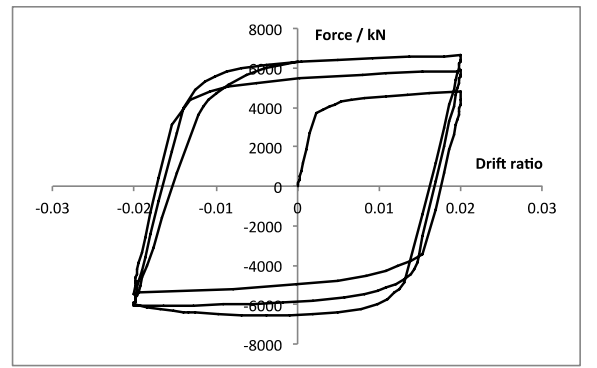

Fig. 4. Hysteretic performance of No.10 wave

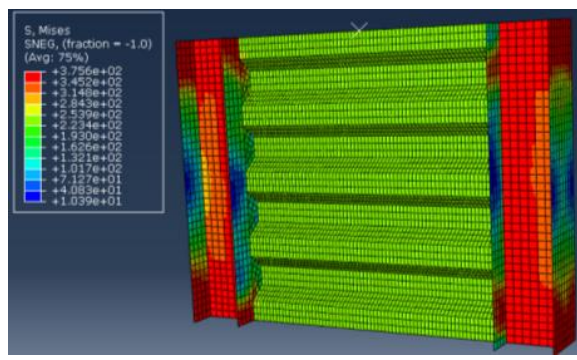

Fig. 5. Von mises stress contour of No.7 wave

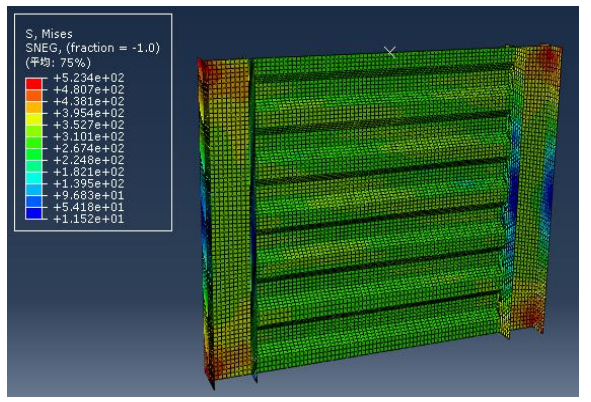

Fig. 6. Von mises stress contour of No.10 wave

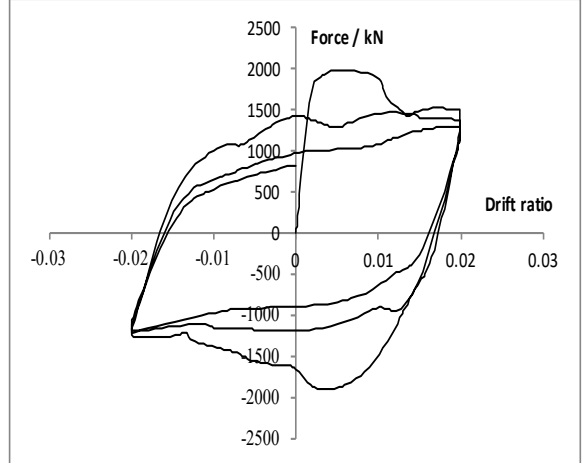

Fig. 7. Typical hysteretic curve of imperfect waves

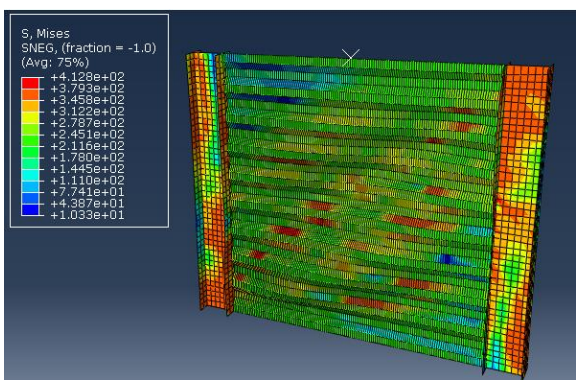

Fig. 8. Typical von mises stress contour of imperfect waves

\section{Parametric study}

\subsection{Effect of height-to-thickness ratio $\mathrm{H} / \mathrm{t}$}

Apparently, the ratio $H / t$ or $B / t$ of corrugated core panel plays an important role in the hysteretic performance of NCW. Excessively large $H / t$ or $B / t$ inevitably results in premature buckling, due to inadequate flexural stiffness. Therefore, a series of relevant FEA is conducted correspondingly, as listed in Table 2, in which the aspect ratios $(B / H)$ are all 1.0.

Table 2. Parametric analysis of $H / t(B / t)$ ratio

\begin{tabular}{cccc}
\hline Wave No. & $\boldsymbol{H} / \boldsymbol{t}(\boldsymbol{B} / \boldsymbol{t})$ & $\boldsymbol{B} / \boldsymbol{H}$ & Buckling \\
\hline \multirow{4}{*}{7} & 150 & & No \\
& 166 & & No \\
& 177 & \multirow{2}{*}{1.0} & No \\
& 199 & & Yes \\
& 221 & & Yes \\
& 332 & & Yes \\
\hline \multirow{4}{*}{10} & 151 & & No \\
& 169 & & No \\
& 188 & \multirow{2}{*}{1.0} & No \\
& 226 & & No \\
& 283 & & Yes \\
& 339 & & Yes \\
\hline
\end{tabular}

\subsection{Effect of aspect ratio $B / H$}

Aspect ratio $(B / H)$ of the corrugated core panel is also taken into consideration in this 
paper. Similarly, influence of aspect ratio is also resort to FEA using Abaqus. Results are tabulated in Table 3, which imply that aspect ratio is the secondary factor compared to $H / t$ or $B / t$ ratio. NCWs would still buckle in cases that $H / t$ or $B / t$ exceeds its upper limits given above. That is to say, as long as $H / t$ and $B / t$ are both kept below 177 for wave 7 and 226 for wave 10, buckling is not going to happen.

Table 3. Parametric analysis of $B / H$ ratio

\begin{tabular}{cccc}
\hline Wave No. & $\boldsymbol{B} / \boldsymbol{H}$ & $\begin{array}{c}\text { max } \\
(\boldsymbol{B} / \boldsymbol{t}, \boldsymbol{H} / \boldsymbol{t})\end{array}$ & Buckling \\
\hline \multirow{4}{*}{7} & 1.0 & 166 & No \\
& 1.7 & 166 & No \\
& 1.0 & 221 & Yes \\
& 1.7 & 221 & Yes \\
& 1.0 & 332 & Yes \\
1.7 & 332 & Yes \\
\hline \multirow{3}{*}{10} & 1.0 & 169 & No \\
& 1.0 & 226 & No \\
& 1.5 & 226 & No \\
& 1.0 & 339 & Yes \\
& 1.5 & 339 & Yes \\
\hline
\end{tabular}

\section{Theoretical Model}

\subsection{Yielding strength}

The corrugated core panel under earthquakes is mainly working in shear. Its theoretical model is thus proposed as shown in Fig. 9.

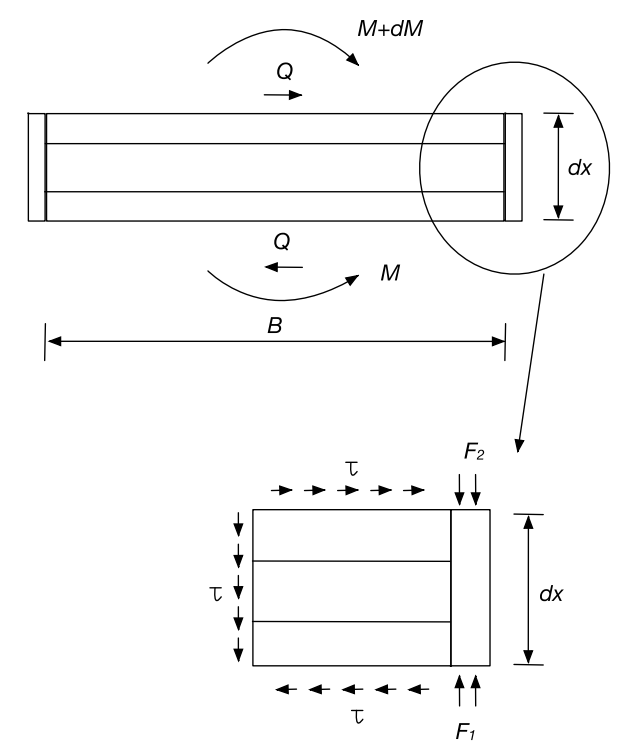

Fig. 9. Analytical model of corrugated core panel

The shear stress in the corrugated core panel is derived in Eq. (1).

$\tau=\frac{F_{2}-F_{1}}{t d x}=\frac{1}{t B} \frac{d M}{d x}=\frac{Q}{t B}$ where $M$ and $Q$ are the moment and shear force, respectively. While $B$ and $t$ are the width and thickness of the panel, respectively.Therefore, the yielding strength is obtained by Eq. (2).

$Q_{y}={ }_{y} t B$

\subsection{Initial stiffness}

When corrugated core panels are subjected to shear forces, distortional deformation of the flute cross section occurs as well as shear deformation. The distortional deformation assumes that a cross section subjected to bending moments deforms symmetrically around a central point of the upper flange and linearly along the ridgeline. Based on the equilibrium of energy, the distortional stiffness value $K_{\mathrm{d}}$ of single wave is derived in Eq. (3).

$K_{d}=\frac{E t^{3} B^{3}}{144 D d^{3} a_{1}^{2}}$

where $E$ is Young's modulus, $D$ is the factor of cross-sectional shapes, $d$ is the wave depth as well as $a 1$, the length of separated horizontal part in single wave, as indicated in Fig. 2.

The shear stiffness value $K_{\mathrm{s}}$ for in-plane shear deformation of single wave is derived by Eq. (4).

$$
K_{s}=\frac{E t B}{4 a_{1}(1+)(1+\cos )}
$$

where $v$ is the Poisson's ratio and $\theta$ stands for the angle of corrugation.

The overall initial stiffness of corrugated core panels is then determined by Eq. (5), in which $n$ equals to the total number of waves.

$$
K=\frac{1}{n\left(\frac{1}{K_{d}}+\frac{1}{K_{s}}\right)}
$$

\subsection{Boundary element}

In this paper, non-buckling steel plate shear wall with corrugated core panel is approximately equivalent to traditional steel plate shear wall which is connected to surrounding beams and columns, as shown in Fig. 10. Thus, by referring to existent research, demand on stiffness of boundary elements in terms of sectional inertia moment $I_{\mathrm{c}}$ is formed, as expressed in Eq. (6). 


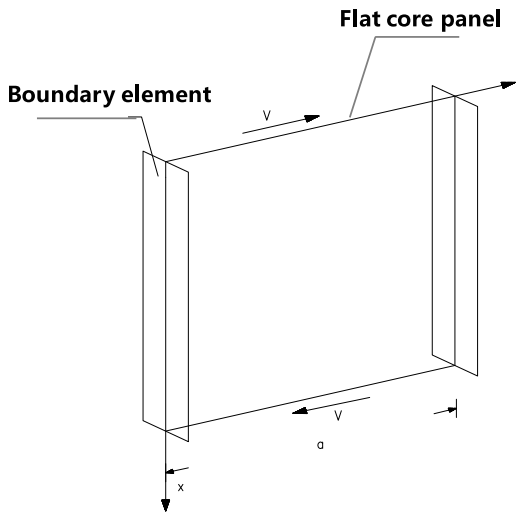

Fig. 10. Equivalence to the four-sided steel plate shear wall with flat core panel

$I_{c}=\frac{0.00307 t d^{4}}{B}$

Knowing that corrugated core panel is subject to shear stress only, which is also uniformly distributed, analytical model for calculating the forces of boundary element is obtained, as shown in Fig. 11. Then, its axial force can be calculated by Eq. (7).

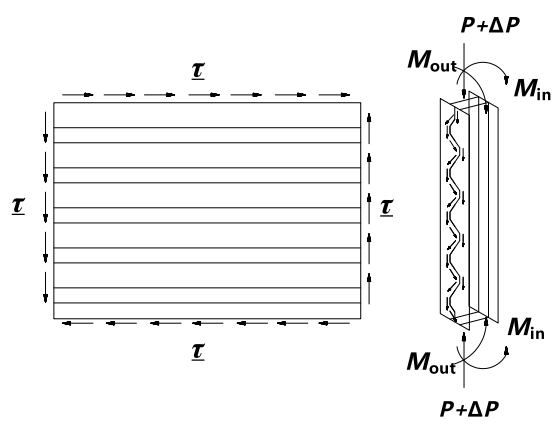

Fig. 11. Analytical model of boundary element

$P=0.5 t H$

On the other hand, the in-plane bending moment is proved to be predicted approximately by Eq. (8) and out-of-plane bending moment by Eq. (9).

$$
\begin{aligned}
& M_{\text {in }}=\frac{6 E I_{c}}{H^{2}} \Delta \\
& M_{\text {out }}=\frac{35 n \tau t d H}{1024}
\end{aligned}
$$

in which $\Delta$ stands for the in-plane lateral displacement of the boundary element.

Accordingly, all the requirements of chinese mandatory code for seismic design of buildings (GB50017-2010) [17] should be satisfied.

\section{Simplified model}

\subsection{Components}

In order to simulate the NCW precisely, especially the relationship between itself and boundary beams, and also to facilitate the design work in traditional procedure when utilizing the NCW, a simplified model consisting of a pair of cross braces and boundary elements with pinned ends is brought forward, as shown in Fig. 12.

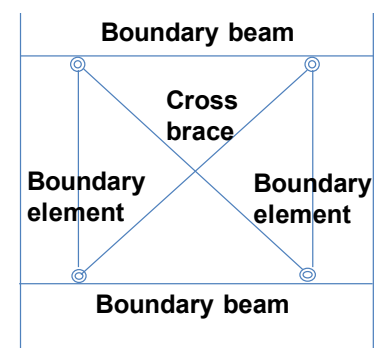

Fig. 12. Simplified model of NCW

\subsection{Design method}

By making the initial stiffness of cross braces be equal to that of NCW, sectional area of cross brace $A_{\mathrm{b}}$ is obtained by Eq. (10).

$A_{b}=\frac{K\left(H^{2}+B^{2}\right)^{\frac{3}{2}}}{2 E B^{2}}$

Similarly, according to the equivalence between yielding strength of above simplified model and that of NCW, the yielding strength of cross brace $f_{\mathrm{b}}$ is derived, as illustrated in Eq. (11).

$$
f_{b}=\frac{V_{y}\left(H^{2}+B^{2}\right)^{\frac{1}{2}}}{2 A_{b} B}
$$

\subsection{Advantage of $\mathrm{NCW}$}

One big advantage of NCW over BRW is that the external shear force imposed on boundary beams is significantly smaller because of the shear-force-transferring action realized by boundary elements of NCW, which are capable of transferring the shear force from upper beam to the bottom base, as shown in Fig. 13. However, additional shear force could not be all transferred to the bottom base, due to a limited axial stiffness of boundary elements. At the same time, the eccentricity between the wall boundary and simplified cross brace would also increase the external shear force that exerted on the beams, while there is no eccentricity in NCW. Therefore, demands on boundary beams would 
be relatively small. The beams would be more economical in NCW application.

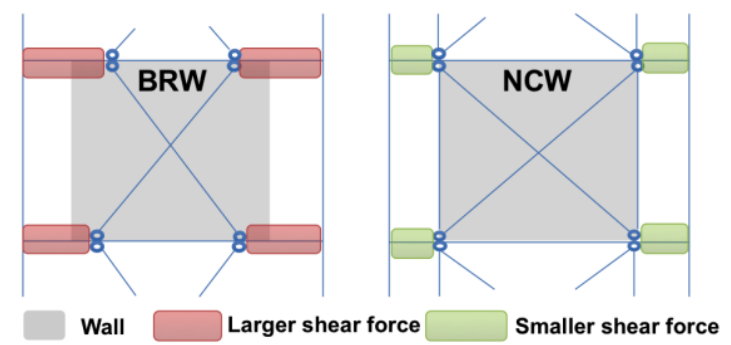

Fig. 13. Advantage of NCW over BRW

\section{Test validation}

\subsection{Specimen design}

Four NCW specimens, as listed in Table 4 were tested to verify the optimal corrugated configuration and hysteretic performance under seismic load in different strain levels. Two specimens adopt wave No.7 and the others adopt No. 10. Difference between those specimens that adopt the same corrugation configuration is height-to-thickness ratio, while one is below the limit and the other is beyond. All specimens are designed to yield before buckling.

Table 4. Parameters of four specimens

\begin{tabular}{ccccc}
\hline $\begin{array}{c}\text { Specimen } \\
\text { No. }\end{array}$ & $\boldsymbol{B} / \boldsymbol{H}$ & $\boldsymbol{H} / \boldsymbol{t}$ & Property & $\begin{array}{c}\text { Wave } \\
\text { No. }\end{array}$ \\
\hline S1 & 0.8 & 325 & Q235 & 7 \\
S2 & 0.5 & 113 & LY225 & \\
\hline S3 & 0.7 & 230 & Q235 & 10 \\
S4 & 0.5 & 113 & LY225 & \\
\hline
\end{tabular}

\subsection{Loading program}

Four specimens are designed to be loaded in a regular pattern based on drift ratio, which is in accordance to the chinese mandatory code for seismic design of buildings (GB50017-2010) [17], as shown in Fig. 14. The loading setup is a self-balanced steel frame, as shown in Fig. 15.

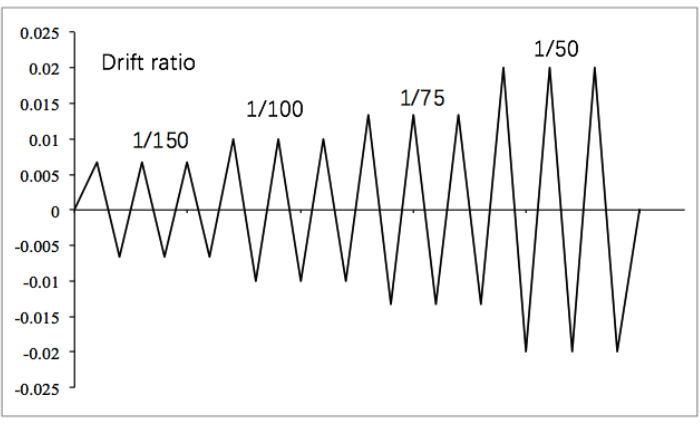

Fig. 14. Loading protocol based on drift ratio

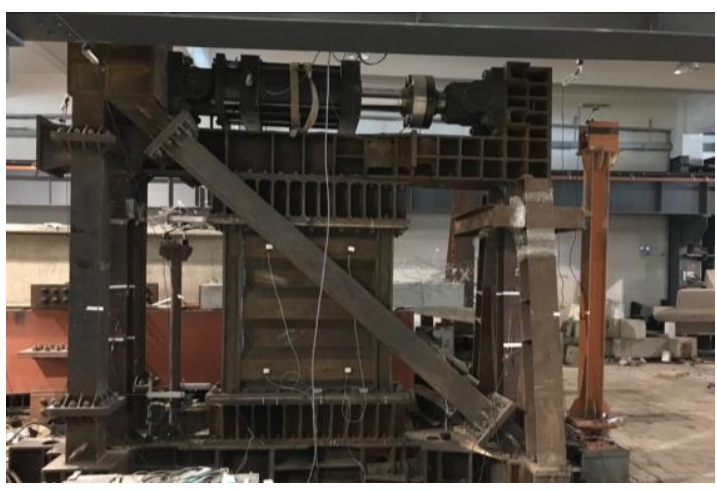

Fig. 15. Self-balanced loading setup

\subsection{Discussion of test results}

Hysteretic curves of four specimens are presented in figures from Fig. 16 to Fig. 19, respectively, from which it could be concluded that all specimens are capable of fully yielding. Those specimens, S2 and S4, show no evident out-of-plane buckling even in a drift ratio of $1 / 50$. While the other two, S1 and S3, did buckle in a global mode under a drift ratio of 1/75 after the specimens were loaded one cycle, as shown in Fig. 20 and Fig. 21.

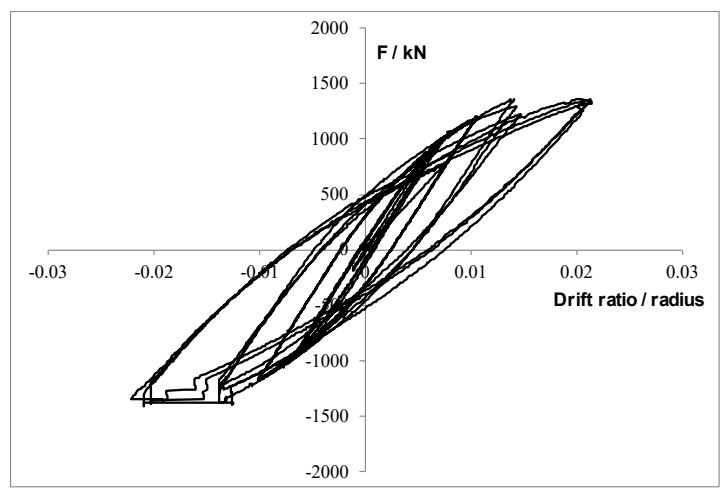

Fig. 16. Hysteretic curve of S1

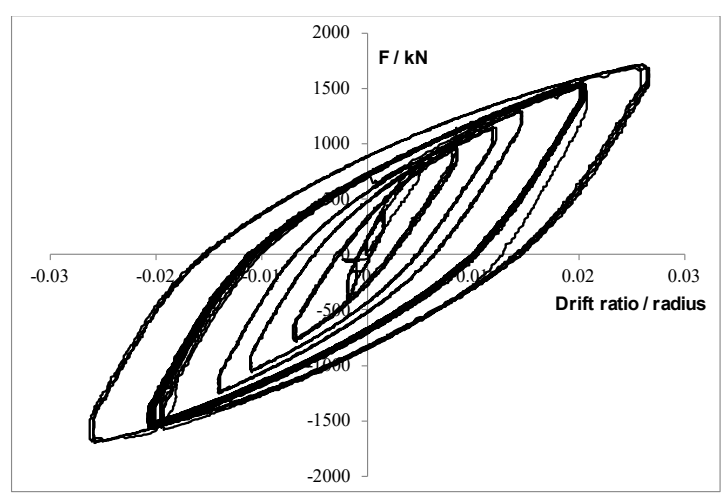

Fig. 17. Hysteretic curve of S2 


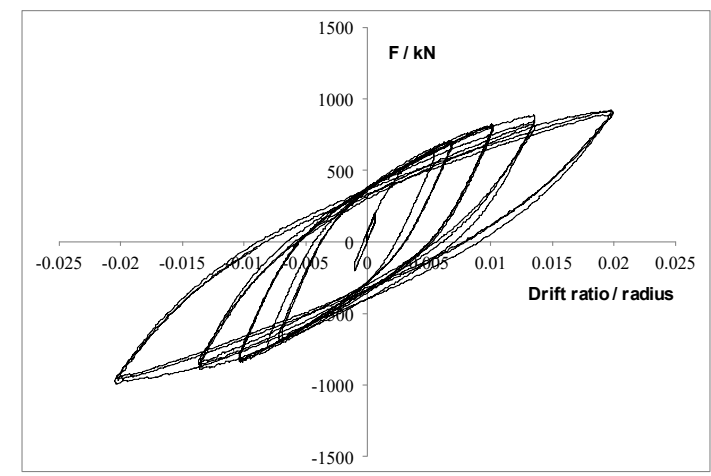

Fig. 18. Hysteretic curve of S3

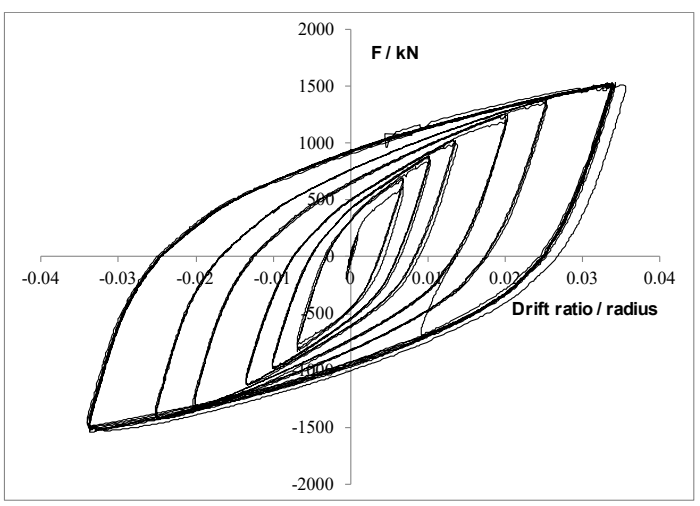

Fig. 19. Hysteretic curve of S4

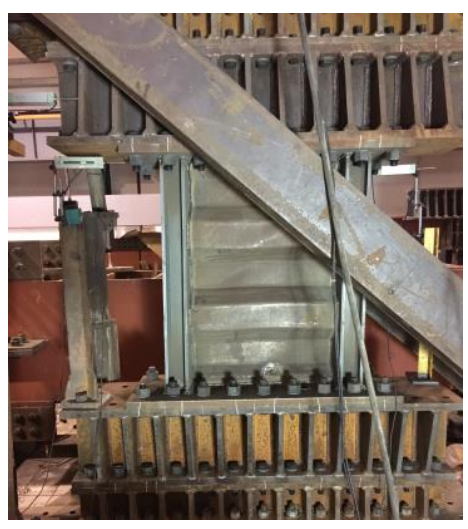

Fig. 20. Buckling of S1 at drift ratio of 1/75

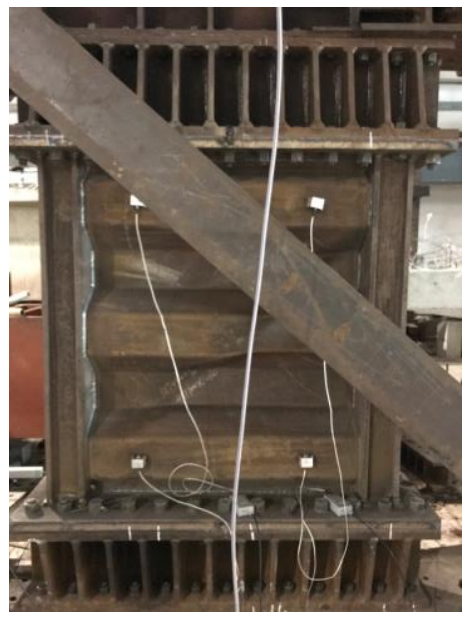

Fig. 21. Buckling of S3 at drift ratio of 1/75
The test results coincide with the theoretical result well in terms of yielding strength $Q_{\mathrm{y}}$ and initial stiffness $K$, with a maximum error of less than $15 \%$, as listed in Table 5 and Table 6 , which in turn prove that the brought-forward theoretical model in this article could predict the yielding strength and initial stiffness properly.

Table 5. Comparison between theoretical and test result in yielding strength

\begin{tabular}{cccc}
\hline & \multicolumn{3}{c}{ Yielding strength } \\
\cline { 2 - 4 } No. & $\begin{array}{c}\text { Theoretical } \\
\boldsymbol{Q}_{\mathbf{y}}\end{array}$ & $\begin{array}{c}\text { Test } \\
\boldsymbol{Q}_{\mathbf{y}}^{\prime}\end{array}$ & $\begin{array}{c}\text { Error } \\
\left(\boldsymbol{Q}_{\mathbf{y}} \mathbf{y}_{\mathbf{y}}\right) / \boldsymbol{Q}_{\mathbf{y}}\end{array}$ \\
\hline S1 & 684 & 722 & $+6 \%$ \\
S2 & 625 & 645 & $+3 \%$ \\
\hline S3 & 416 & 455 & $+9 \%$ \\
S4 & 379 & 411 & $+8 \%$ \\
\hline
\end{tabular}

Table 6. Comparison between theoretical and test result in initial stiffness

\begin{tabular}{cccc}
\hline & \multicolumn{3}{c}{ Initial stiffness } \\
\cline { 2 - 4 } No. & $\begin{array}{c}\text { Theoretical } \\
\boldsymbol{K}\end{array}$ & $\begin{array}{c}\text { Test } \\
\boldsymbol{K}\end{array}$ & $\begin{array}{c}\text { Error } \\
\left(\boldsymbol{K}^{\prime}-\boldsymbol{K}\right) / \boldsymbol{K}\end{array}$ \\
\hline S1 & 307 & 287 & $-7 \%$ \\
S2 & 465 & 411 & $-12 \%$ \\
\hline S3 & 283 & 246 & $-13 \%$ \\
S4 & 377 & 324 & $-14 \%$ \\
\hline
\end{tabular}

\section{Conclusions}

Above all, the concept of non-buckling steel plate shear wall with corrugated core panel was first brought forward in this article and realized in both theoretical and experimental way. Based on research that have been done so far, several conclusions could be made just as follows.

(1) Two optimal corrugation configurations were parametrically obtained and recommended for the core panel of non-buckling steel plate shear walls.

(2) Non-dimensional parameters such as heightto-thickness ratio and width-to-thickness have been proved to be the most decisive factors of guaranteeing the "non-buckling". As long as they are below the critical values recommended in this paper, unexpected buckling is not going to happen.

(3) Theoretical approaches to calculate yielding strength and initial stiffness were derived, as well as a theoretical design method for boundary elements. It has presented a good correlation with the test results with the maximum error between the theoretical and experimental results less than $15 \%$. 
(4) Corresponding simplified model for NCW which consists of a pair of cross braces and boundary elements with pinned ends was introduced. Formulas to determine the cross section of cross braces and boundary elements were given based on the principle of equivalent yielding strength and initial stiffness.

(5) Finally, four specimens with the suggested optimal corrugation configuration were tested cyclically. All specimens were designed and showed that they could achieve fully yielding before premature buckling. Two specimens with a height-to-thickness ratio larger than the recommended limit have exhibited inevitable buckling, while the other two with a smaller height-to-thickness ratio showed ideal energyabsorption capability and no evident buckling was observed even under an inter-story drift of $2 \%$.

\section{References}

[1] Elgaaly M, Liu Y. Analysis of thin steel plate shear walls[J]. Journal of Structural Engineering, 1997; 123(11):1487-1496.

[2] Jin HJ, Li GQ, Sun FF, Lu Y. Research on buckling restrainers in buckling-restrained steel plate shear walls (I) - theoretical model and stiffness requirement. China Civil Engineering Journal, 2016; 49(6):38-45.

[3] Li GQ, Jin HJ, Sun FF, Lu Y. Research on buckling restrainers in buckling-restrained steel plate shear walls (II) - strength requirement and experimental validation. China Civil Engineering Journal, 2016; 49(7):49-56.

[4] Nilson AH. Shear diaphragms of light gage steel. Journal of the Structural Division, 1960; 86(11):111-140.

[5] Davies JM. Calculation of steel diaphragm behaviour. Journal of the Structural Division, 1976; 102(7):1401-1430.

[6] Easley JT. Strength and stiffness of corrugated metal shear diaphragms. Journal of the Structural Division, 1977; 103(1):169-180.
[7] Fazio P, Ha K, Chockalingam S. Strength of cold-formed steel shear diaphragms. Canadian Journal of Civil Engineering, 1978; 6(1):5-17.

[8] Davies JM. A general solution for the shear flexibility of profiled sheets. I: Development and verification of the method. Thin-Walled Structures, 1986; 4(1):41-68.

[9] Wright HD, Hossain KMA. In-plane shear behaviour of profiled steel sheeting. Thin-Walled Structures, 1997; 29(1-4):79-100.

[10]Fülöp LA, Dubina D. Performance of wall-stud cold-formed shear panels under monotonic and cyclic loading: Part I: Experimental research. Thin-Walled Structures, 2004, 42(2):321-338.

[11]Fülöp LA, Dubina D. Performance of wall-stud cold-form shear panels under monotonic and cyclic loading Part II: Numerical modeling and performance analysis. Thin-Walled Structures, 2004; 42(2):339-349.

[12] Tipping S, Stojadinovic B. Innovative corrugated steel shear walls for multi-story residential buildings[C]// Proceedings of 14th World Conference on Earthquake Engineering (WCEE'14), Beijing, 2008, 210-218.

[13] Vora H, Yu C. Pilot research on cold-formed steel framed shear wall assemblies with corrugated sheet steel sheathing[C]// Proceedings of 19th International Specialty Conference on Cold-Framed Steel Structures, St. Louis, 2008, 322-338.

[14] Emami F, Mofid M, Vafai A. Experimental study on cyclic behavior of trapezoidally corrugated steel shear walls. Engineering Structures, 2013; 48(48):750-762.

[15] Shimizu N, Kanno R, Ikarashi K, et al. Cyclic Behavior of Corrugated Steel Shear Diaphragms with End Failure. Journal of Structural Engineering, 2013; 139(5):796-806.

[16] Abaqus. Analysis user's manual, version 6.10. Simulia; 2011.

[17] GB50011-2010, Code for seismic design of buildings, China Building Industry Press, Beijing, (2010). 